\title{
Resolution of syringomyelia in ten cases of "up-and-down Chiari malformation" after posterior fossa decompression
}

\author{
José Alberto Gonçalves da Silva', Luiz Ricardo Santiago Melo', \\ Antônio Fernandes de Araújo ${ }^{1}$, Adailton Arcanjo dos Santos Jr²
}

\begin{abstract}
The authors describe ten cases of syringomyelia without hindbrain herniation depicted by preoperative magnetic resonance imaging (MRI) in supine position. However, the herniation was observed in all cases during the operation with the patient in sitting position. The postoperative MRI revealed an intense reduction of the syrinx in all patients, as well as it was also observed a clinical amelioration in all cases. The surgical treatment was based on a large craniectomy with the patient in sitting position, tonsillectomy, large opening of the fourth ventricle and duraplasty with creation of a large cisterna magna.
\end{abstract}

Key words: Chiari malformation, syringomyelia, craniovertebral decompression.

Resolução de siringomielia em dez casos de malformação de Chiari observada apenas com o paciente em posição sentada durante a descompressão da fossa posterior

\section{RESUMO}

Os autores descrevem 10 casos de siringomielia sem herniação do rombencéfalo, observada na ressonância magnética realizada em decúbito dorsal. Por outro lado, a herniação foi observada em todos os pacientes durante a operação com o paciente em posição sentada. A ressonância magnética pós-operatória evidenciou redução da cavidade siringomiélica nos dez pacientes, bem como foi observada melhora clínica em todos os casos. O tratamento cirúrgico consistiu de craniectomia ampla da fossa posterior, tonsilectomia, abertura ampla do quarto ventrículo e duroplastia com a criação de ampla cisterna magna.

Palavras-chave: malformação de Chiari, siringomielia, descompressão craniovertebral.

The neural dysgenesis, later named as Chiari malformation (CM), was initially described by Cleland ${ }^{1}$ and afterwards by Chiari $^{2,3}$. Chiari ${ }^{3}$ reported the anomalies of the hindbrain found in 63 cases of hydrocephalus and he defined the spectrum of anomalies which is now recognized as CM.

In the original description, Type I was characterized by downward displacement of the cerebellar tonsils and the medial portions of the inferior cerebellar lobes which were accompanied by the medulla oblongata into the vertebral canal. The Type II showed downward displacement of the cerebellar tonsils, portions of the inferior vermis, pons, medulla oblongata and, at least, a part of the lengthened fourth ventricle, which reached the disc $\mathrm{C} 4-\mathrm{C} 5$, into the vertebral canal. In Type III, the hydrocephalic cerebellum, pons and medulla were found inside a cervical meningocele (hydroencephaloceles cerebellaris cervicalis), through a spina bifida of the first three cervical vertebrae. In Type IV, there was hypoplasia of the cerebellum without herniation of the cerebellar structures into the vertebral canal.

In this report, the authors present ten 
cases of syringomyelia (SM) without hindbrain herniation depicted by magnetic ressonace imaging (MRI) in supine position. Nevertheless, this herniation was observed in all patients during the operation in the sitting position. Otherwise, the authors observed an intense reduction of the size of the syrinx, as well as a clinical amelioration in all patients after surgery.

Iskandar et al. ${ }^{4}$ reported on five pediatric cases of SM without hindbrain herniation. All patients improved after undergoing posterior fossa decompression. Kyoshima et al. ${ }^{5}$ described four similar cases with a good recovery of the patients after the decompressive operation. The authors named the impacted cisterna magna by the tonsils of "tight cisterna magna" and designated Iskandar's et al. description as "Chiari 0 malformation". While these authors did not mention the surgical position of the patients, Iskandar et al. ${ }^{4}$ referred that all patients underwent craniocervical decompression as previously described by Oakes.

\section{METHOD}

This study is based on a retrospective review of the patients, five men and five women, with SM without hindbrain herniation. However, this herniation came out during the surgery with the patient in the sitting position (Fig 1). All patients underwent craniocervical decompression previously described by Gonçalves da Silva et al. ${ }^{6}$. This

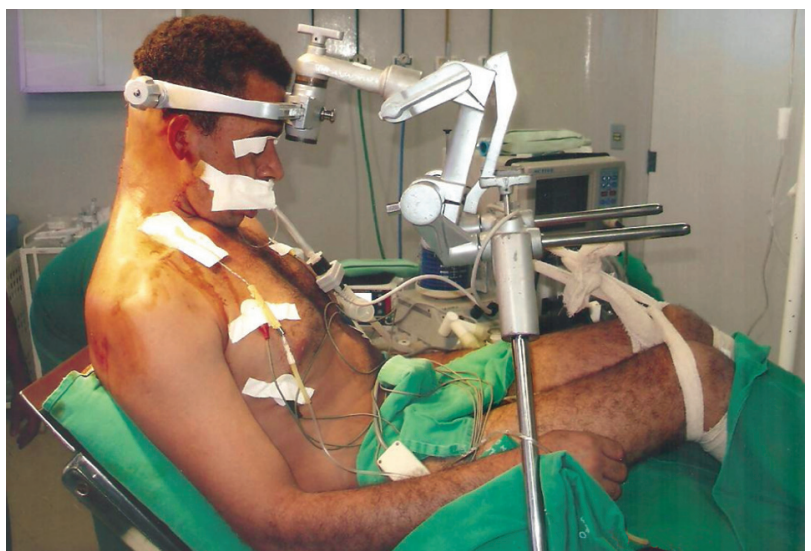

Fig 1. Patient in the sitting position.

study was approved by the Ethics Committee of Hospital Unimed João Pessoa.

The surgery consisted of a large craniectomy, dissection of the cerebellar tonsils and the regional arteries, large opening of the fourth ventricle, intrapial aspiration of the cerebellar tonsils, suture of the residual pial sacs to the lateral dura mater in ascending position and, finally, a dural grafting was performed with the use of bovine pericardium creating, in this way, a large cisterna magna (Figs 2 and 3).
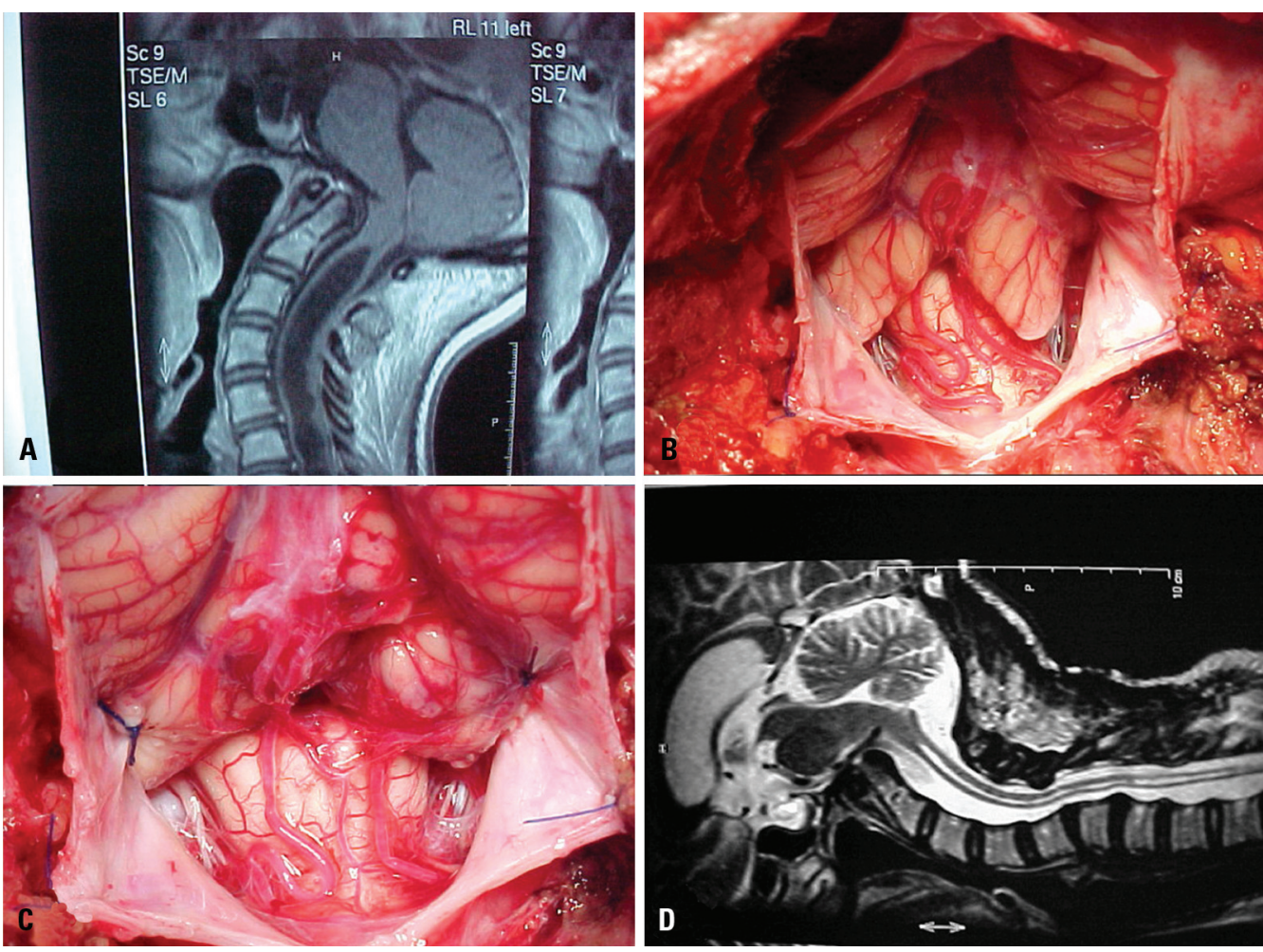

Fig 2. [A] Preoperative MRI demonstraiting syringomyelia without tonsillar herniation. [B] Herniation of the cerebellar tonsils with the patient in sitting position. [C] Tonsilectomy and large opening of the fourth ventricle. [D] Postoperative MRI showing dramatic reduction of the syringomyelic cavity. 


\section{RESULTS}

Ten consecutive patients with syringomyelia and no hindbrain herniation in the supine position were presented. Although, this herniation was observed in all patients during the surgery in the sitting position. All the cases were followed with clinical studies and craniocervical MRI for a mean of 2.8 years and a range of four months to seven years. The age at surgery ranged from 26 to 59 years, with a mean of 35.4 years. All the patients showed significant improvement in symptoms, signs, and syrinx's size in the postoperative follow-up.

The clinical symptoms observed by the preoperative examination are showed in Table 1, the clinical signs in Table 2 and the surgical findings in Table 3.

Six out of the ten cases were associated with basilar impression (BI), as well as four cases were associated with herniation only of the cerebellar tonsils and these were classified as Chiari I malformation. In another six cases were observed partial herniation of the hindbrain structures and were classified as Chiari II malformation. The tonsillar herniation of the ten cases varied from the end of $\mathrm{C} 1$ to the beginning of $\mathrm{C} 3$. The vascular network anomalies in eight cases were characterized by a left and large posterior inferior cerebellar artery (PICA) in two cases, only a right and large PICA in one case, a large PICA on the right side and one hypoplasic on the left in two cases and, finally, looping sign on the PICAS in three cases.

\section{DISCUSSION}

In this report, the authors describe ten cases of SM without hindbrain herniation showed by the MRI in the supine position. However, this herniation was observed in all patients during the surgery in the sitting position.
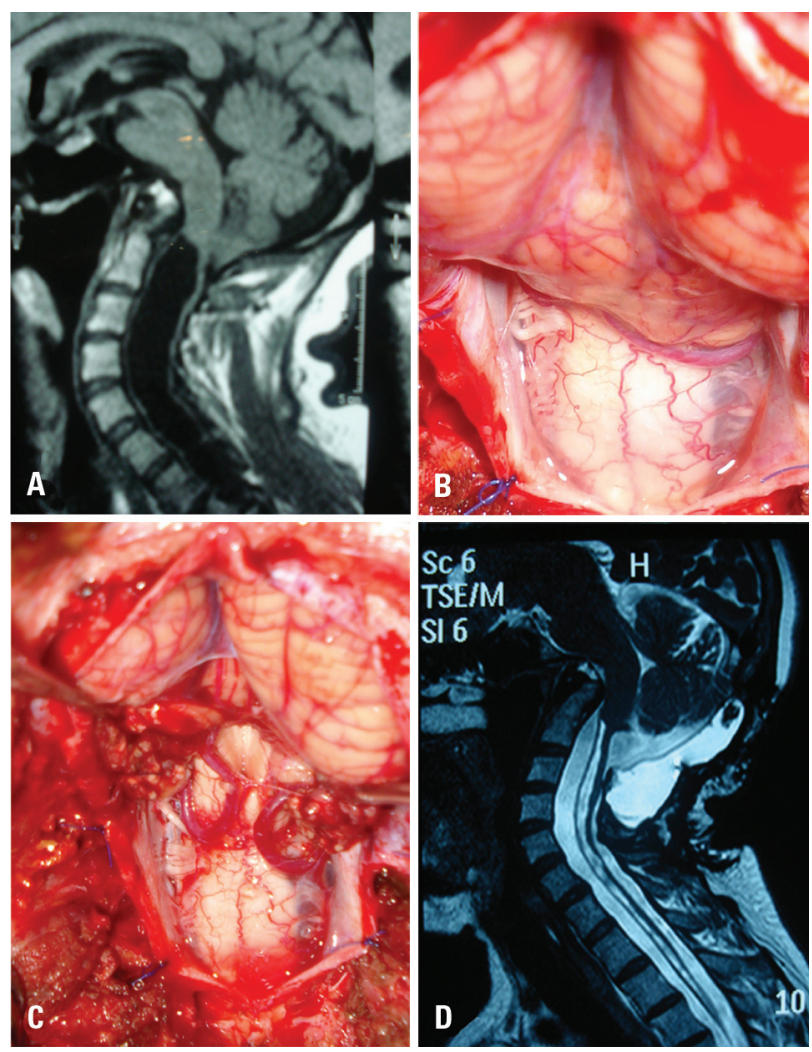

Fig 3. [A] Preoperative MRI depicting a large syringomyelic cavity without tonsillar herniation. $[\mathrm{B}]$ Tonsillar herniation and dilation of the medulla. [C] Tonsilectomy and large opening of the fourth ventricle. [D] Reduction of the syringomyelic cavity, creation of a large cisterna magna, and pseudomeningocele.

This kind of "up-and-down CM" was observed also in cases without $\mathrm{SM}^{7,8}$.

Iskandar et al. ${ }^{4}$, on the other side, reported on five pediatric cases of SM without hindbrain herniation; all pa-

Table 1. Clinical symptoms observed in ten cases of "up-and-down Chiari malformation".

\begin{tabular}{|c|c|c|c|c|c|c|c|}
\hline Symptoms & Cases number & $\mathrm{R}$ & $\%$ & A & $\%$ & U & $\%$ \\
\hline Headache & 6 & 5 & 83 & - & - & 1 & 16.6 \\
\hline Pain in the neck & 6 & 5 & 83 & - & - & 1 & 16.6 \\
\hline Stiffness of the neck & 5 & 5 & 100 & - & - & - & - \\
\hline Vertigo & 7 & 7 & 100 & - & - & - & - \\
\hline Dysfagia & 3 & 3 & 100 & - & - & - & - \\
\hline Rhinolalia & 2 & - & - & - & - & 2 & 100 \\
\hline Numbness of limbs & 8 & 5 & 62.5 & - & - & - & - \\
\hline Limbs' paresthesia & 10 & 1 & 10 & 8 & 80 & 1 & 10 \\
\hline Gait disturbances & 7 & 2 & 28.5 & 3 & 42.8 & 2 & 28.5 \\
\hline Sexual disturbances & 4 & 1 & 25 & - & - & 3 & 75 \\
\hline Anhidrosis & 7 & 4 & 57.1 & - & - & 3 & 42.8 \\
\hline Hiperidrosis & 1 & - & - & - & - & 1 & 100 \\
\hline Syringomyelic aches & 1 & - & - & - & - & 1 & 100 \\
\hline
\end{tabular}

R: regressed; A: amelioration; U: unchanged. 
Table 2. Clinical signs observed in ten cases of "up-and-down Chiari malformation".

\begin{tabular}{|c|c|c|c|c|c|c|c|}
\hline Signs & Cases number & $\mathrm{R}$ & $\%$ & A & $\%$ & $\mathrm{U}$ & $\%$ \\
\hline Lesion of the $\mathrm{V}^{\text {th }}$ nerve & 3 & 3 & 100 & - & - & - & - \\
\hline Nystagmus & 1 & - & - & - & - & 1 & 100 \\
\hline Abolition of gag and palatal reflexes & 5 & - & - & - & - & 5 & 100 \\
\hline Lesion of $\mathrm{XI}^{\text {th }}$ nerve & 9 & 2 & 22.2 & - & - & 7 & 77.7 \\
\hline Hypotonia & 6 & 1 & 16.6 & - & - & 5 & 83.3 \\
\hline Spasticity & 9 & 6 & 66.6 & 2 & 22.2 & 1 & 11.1 \\
\hline Paresis of limbs & 10 & 2 & 20 & 8 & 80 & - & - \\
\hline Hyperreflexia & 9 & - & - & - & - & 9 & 100 \\
\hline Hoffmann's sign & 7 & 3 & 42.8 & - & - & 4 & 57.1 \\
\hline Babinski's sign & 6 & 3 & 50 & - & - & 3 & 50 \\
\hline Rossolimo's sign & 6 & 3 & 50 & - & - & 3 & 50 \\
\hline Unsteady gait & 7 & 2 & 28.5 & 3 & 42.8 & 2 & 28.5 \\
\hline Hypopallesthesia & 10 & - & - & - & - & 10 & 100 \\
\hline Syringomyelic dissociation & 9 & 3 & 33.3 & 3 & 33.3 & 3 & 33.3 \\
\hline Atrophy & 10 & - & - & 1 & 10 & 9 & 90 \\
\hline
\end{tabular}

R: regressed; A: amelioration; U: unchanged.

Table 3. Surgical findings in ten cases of "up-and-down Chiari malformation".

\begin{tabular}{lcc}
\hline Findings & Cases number & $\%$ \\
\hline Thinning of the occipital bone & 2 & 20 \\
Thickening of the occipital bone & 1 & 10 \\
Pulseless dura mater & 4 & 40 \\
Arachnoiditis & 7 & 70 \\
Block of the foramen of Magendie & 7 & 70 \\
Herniation of the brainstem & 6 & 60 \\
Herniation of the tonsils in sitting position & 10 & 100 \\
Vascular network anomaly & 8 & 80 \\
Communication of the fourth ventricle with the hydromyelic cyst & 4 & 40 \\
Syringobulbia & 1 & 10 \\
\hline
\end{tabular}

tients improved after undergoing posterior fossa decompression. The authors hypothesize the rare occurrence of SM resulting from a Chiari-like pathophysiological condition, but lacking a hindbrain herniation.

Newton et al. ${ }^{9}$ described anomalies in the fourth ventricle drainage based on 15 personal adult cases of SM. In 12 out of 14 patients who underwent posterior fossa exploration were found a CM or an occluded foramen of Magendie, or both together. In three cases without a Chiari anomaly there was no foramen of Magendie. Probably that was the first description of the presence of a SM without hindbrain herniation.

Many theories have been presented in attempt to explain the genesis of SM. The development of SM has been observed in relation to congenital or acquired lesions at the foramen magnum or at the spine. Different lesions at the foramen magnum have been commonly reported as $\mathrm{CM}, \mathrm{BI}$, membranous occlusion of the foramen of Magendie, arachnoiditis and tight cisterna magna ${ }^{4,5,10}$.

Gardner's ${ }^{11-14}$ hydrodynamic theory explains the pathogenesis and the development mechanism of communicating central canal cavities, based on foraminal obstruction of the fourth ventricle, which enhanced pulsatile waves in the ventricle (water-hammer-wave) forcing the obex to open and the central canal to expand.

Williams ${ }^{15-17}$ proposed the mechanism of the craniospinal pressure dissociation to explain the development of communicating central canal cavities. Cough and sneeze reflexes would increase the intra-abdominal and intrathoracic pressures, increasing the venous pressure and fur- 
ther dilating the epidural venous plexus. This would compress the dural sac, displacing, as a result, the cerebrospinal fluid (CSF), and pushing into the cranial cavity which returns rapidly to the spinal subarachnoid space, as soon as the pressure brought down to the normal levels. In case of tonsillar herniation, the CSF return would be blocked by the cerebellar tonsils which would then work as a valve, occluding the foramen magnum. At this point, the central canal of spinal cord - under a lower pressure than that of the intracranial cavity - would become the ideal place to accommodate CSF. The perpetuation of the phases of craniospinal pressure dissociation causes the formation and maintenance of SM.

Ball and Dayan ${ }^{18}$ admitted that CSF penetrates in the central canal of the spinal cord through Virchow-Robin spaces or through the dorsal roots, creating, in this way, the syringomyelic cavity.

The symptomatology appears as the result of the expansion of the syringomyelic cavity and the gliosis affecting the intramedullary and/or the brainstem structures. Milhorat et al. ${ }^{19}$ measured the pressure inside the syringomyelic cavity, and suggested that the distention would depend on different degrees of intramedullary pressure, causing lesion of long tracts, gray matter and microcirculation. The involvement of the anterior horn gives rise to fibrillation, fasciculation, muscular weakness and atrophy. However, the compression of the posterior horn and ventral decussation will give origin to syringomyelic dissociation, and, on the other hand, commitment of the sympathetic connection will result in Claude BernardHorner syndrome. With the expansion of the cavity, the spinal cord white matter will be compressed, causing a lesion of the pyramidal and extrapyramidal tracts and dorsal columns.

Regarding the surgical technique, all patients of our casuistic of 360 cases of craniovertebral malformations, were operated in the sitting position what facilitates the surgical procedure. Gardner e Goodall ${ }^{11}$ used this type of position for the operation of 13 out of 17 patients with CM. Later, Gardner ${ }^{13}$ used the same position for the surgical treatment of 74 patients with SM, and on this occasion he introduced the dural graft for the protection of the posterior fossa structures.

The extension of the craniectomy varies in the literature. Because of the small size of the posterior fossa in the presence of $\mathrm{BI}$ and/or CM, especially when both anomalies are present, we prefer to use a large craniectomy which extends cranially to the transverse sinus commonly situated lower than those in normal persons - and laterally to $3-4 \mathrm{~cm}$ from the midline. The reason for this large opening is to increase both of the posterior fossa and the cisterna magna, commonly absent in cases of hindbrain herniation, permitting, in this way, the her- niated portions of the cerebellum and brainstem to migrate upwards.

Batzdorf ${ }^{20}$ and Duddy and Williams ${ }^{21}$ state that the herniation of the cerebellar structures and brainstem, as observed in the postoperative period, are attributed to a large craniectomy. A small craniectomy, on the contrary, might have prevented a decompression from maintained the CSF blockade and perpetuating the craniospinal pressure dissociation. Duddy and Williams ${ }^{21}$, however, using a smaller craniectomy, revealed a frequent downwards migration of the cerebellum and brainstem, and pointed this out as a cause of poor results. These authors observed a downward migration of the posterior fossa structures in $53 \%$ of their patients, whereas no change was noticed in $41 \%$, and the ascent of the hindbrain was observed in only one case.

Sahuquillo et al. ${ }^{10}$ compared the results obtained in 10 cases in which a small craniectomy was performed, with other 10 patients that underwent an extensive craniectomy. An upward migration of the cerebellum and brainstem was observed in all the last patients, while in those which a small craniectomy was performed there was a downward migration in 7 patients.

The volume of the posterior fossa is notoriously reduced in cases of $\mathrm{BI}$ and/or CM, as described firstly by Ackermann $^{22}$. Milhorat et al. ${ }^{23}$ verified a decrease of $13.4 \mathrm{ml}$ in the volume of the posterior fossa and $40 \%(10.5 \mathrm{ml})$ in the CSF volume of this region, followed by many authors ${ }^{24-29}$.

As to postoperative complications the authors observed pseudomeningocele in 4 cases, from these 2 were reoperated and one associated with hydrocephalus underwent a ventriculoperitoneal shunt. In just one case of pseudomeningocele depicted by postoperative MRI without compression signs of the hindbrain structures, the operation was not indicated.

Iskandar et al. ${ }^{4}$ called attention for idiopathic SM that respond to posterior fossa decompression. The authors hypothesize the rare occurrence of SM resulting from a Chiari-like pathophysiology condition but lacking a hindbrain herniation. We can suggest that the pathophysiology of our cases depend on the "up-and-down CM". As well as, we could suggest that patients with craniovertebral anomalies should undergo a preoperative MRI in orthostatic position to detect hindbrain herniation depending on the body position.

\section{REFERENCES}

1. Cleland J. Contribution to the study of spina bifida, encephalocele, and anencephalus. J Anat Physiol 1883;17:257-292.

2. Chiari H. Über Veränderungen des Kleinhirns infolge von Hydrocephalie des Grosshirns. Dtsch med Wschr 1891;17:1172-1175.

3. Chiari H. Veränderungen des Kleinhirns, des Pons und der Medulla oblongata in Folge von congenitaler Hydrocephalie des Grosshirns. Dtsch med Wschr 1895;42:71-116

4. Iskandar BJ, Hedlund GL, Grabb PA, Oakes WJ. The resolution of syringohy dromyelia without hindbrain herniation after posterior fossa decompression. J Neurosurg 1998;89:212-216. 
5. Kyoshima K, Kuroyanagi T, Oya F, Kamijo Y, El-Noamany H, Kobayashi S. Syringomyelia without herniation: tight cisterna magna. Report of four cases and a review of the literature. J Neurosurg (Spine 2)2002;96:239-249.

6. Gonçalves da Silva JA, Holanda MMA. Basilar impression, Chiari malformation and syringomyelia: a retrospective study of 53 surgically treated patients. Arq Neuropsiquiatr 2003;61:368-375

7. Gonçalves da Silva JA, Holanda MMA, Pereira CB, Leiros MD, Araújo AF, Bandeira E. Retropulsion and vertigo in the Chiari malformation: case report. Arq Neuropsiquiatr 2005:63:870-873.

8. Gonçalves da Silva JA, da Costa MDL, Melo LR, Araújo AF, Almeida EB. Impacted cisterna magna without syringomyelia associated with lancinating headache, throbbed nuchal pain and paraparesis treated by posterior fossa decompression. Arq Neuropsiquiatr 2007;65:1228-1232.

9. Newton EJ. Syringomyelia as a manifestation of defective fourth ventricular drainage. Ann R Coll Surg Engl 1969;44:194-213.

10. Sahuquillo J, Rubio E, Poca MA, Rovira A, Rodriguez-Baeza A, Cervera C. Posterior fossa reconstruction: a surgical technique for the treatment of Chiar I malformation and Chiari I/syringomyelia complex- preliminary results and magnetic resonance imaging quantitative assessment of hindbrain migration. Neurosurgery 1994;35:874-885

11. Gardner J, Goodall RJ. The surgical treatment of Arnold-Chiari malformation in adults: an explanation of its mechanism and importance of encephalography in diagnosis. J Neurosurg 1950;3:199-206.

12. Gardner J, Angel J. The mechanism of syringomyelia and its surgical correction. Clin Neurosurg 1958;6:131-140.

13. Gardner J. Hydrodynamic mechanism of syringomyelia: its relationship to myelocele. J Neurol Neurosurg Psychiatry 1965:28:247-259.

14. Gardner J, Mc Murry FG. "Non-communicating" syringomyelia: a non-existent entity. Surg Neurol 1976;6:251-256.

15. Williams $B$. The distending force in the produgtion of "communicating syringomyelia". Lancet 1969;26:189-193.
16. Williams B. The valvular action of the Arnold-Chiari malformation. In: Brock M, Dietz H (Eds). Intracranial pressure. Berlin: Springer, 1972:338-442.

17. Williams B. A critical appraisal of posterior fossa surgery for communicating syringomyelia. Brain 1978;101:223-250.

18. Ball MJ, Dayan AD. Pathogenesis of syringomyelia. Lancet 1972;2:799-801.

19. Milhorat TH, Capocelli Jr AL, Kotzen RM, Bolognese P, Heger IM, Cottrell JE. Intramedullary pressure in syringomyelia: clinical and pathophysiological correlates of syrinx distension. Neurosurgery 1997;5:1102-1110.

20. Batzdorf U. Chiari I malformation with syringomyelia: evaluation of surgical therapy by magnetic resonance imaging. J Neurosurg 1988;68:726-730.

21. Duddy MJ, Williams B. Hindbrain migration after decompression for hindbrain hernia: a quantitative assessment using MRI. Brit J Neurosurgery 1991;5: 141-152.

22. Ackermann IF. Über die Kretinen, eine besondere Menschenabart in den Alpen. Gothe, in der Ettingerschen Buchhandlung, 1790

23. Milhorat TH, Chou MW, Trinidad EM, et al. Chiari I malformation redefined: clinical and radiographic findings for 364 symptomatic patients. Neurosurgery 1999:44:1005-1017.

24. Nyland $\mathrm{H}$, Krogness KG. Size of posterior fossa in Chiari type I malformation in adults. Acta Neurochirurgica 1978;40:233-242.

25. Marin-Padilla M, Marin-Padilla TM. Morphogenesis of experimentally induced Arnold-Chiari malformation. J Neurol Sci 1981;50:29-55.

26. Schady W, Metcalfe RA, Butler P. The incidence of craniocervical bony anomalies in the adult Chiari malformation. J Neurol Sci 1987:82:193-203.

27. Vega A, Quintana F, Berciano J. Basichondrocranium anomalies in adult Chiari type I malformation: a morphometric study. J Neurol Sci 1990;99:137-145.

28. Marin-Padilla M. Cephalic axial skeletal-neural dysraphic disorders: embryology and pathology. Can J Neurol Sci 1991;18:153-169.

29. Badie B, Mendoza D, Batzdorf U. Posterior fossa volume and response to suboccipital decompression in patients with Chiari I malformation. Neurosurgery 1995;37:214-218. 